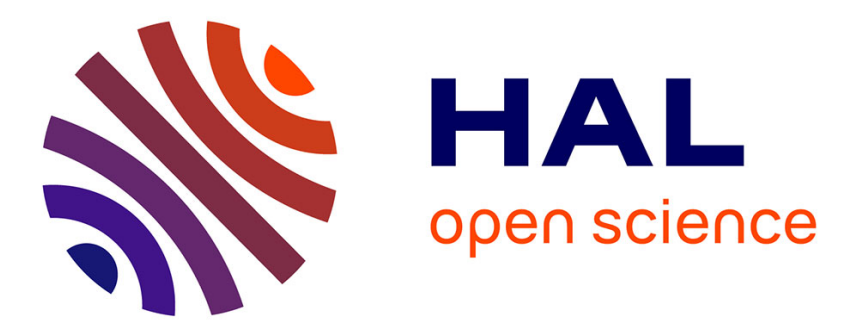

\title{
Enhanced electrocaloric effect near polymorphic phase boundary in lead-free potassium sodium niobate ceramics
}

Xiangjian Wang, Jiagang Wu, Brahim Dkhil, Baixiang Xu, Xiaopeng Wang, Guohua Dong, Guang Yang, Xiaojie Lou

\section{To cite this version:}

Xiangjian Wang, Jiagang Wu, Brahim Dkhil, Baixiang Xu, Xiaopeng Wang, et al.. Enhanced electrocaloric effect near polymorphic phase boundary in lead-free potassium sodium niobate ceramics. Applied Physics Letters, 2017, 110 (6), pp.063904. 10.1063/1.4976026 . hal-02317037

\section{HAL Id: hal-02317037 \\ https://hal-centralesupelec.archives-ouvertes.fr/hal-02317037}

Submitted on 24 Aug 2020

HAL is a multi-disciplinary open access archive for the deposit and dissemination of scientific research documents, whether they are published or not. The documents may come from teaching and research institutions in France or abroad, or from public or private research centers.
L'archive ouverte pluridisciplinaire HAL, est destinée au dépôt et à la diffusion de documents scientifiques de niveau recherche, publiés ou non, émanant des établissements d'enseignement et de recherche français ou étrangers, des laboratoires publics ou privés. 


\section{Enhanced electrocaloric effect near polymorphic phase boundary in lead-free potassium sodium niobate ceramics}

Cite as: Appl. Phys. Lett. 110, 063904 (2017); https://doi.org/10.1063/1.4976026

Submitted: 17 December 2016 . Accepted: 28 January 2017 . Published Online: 08 February 2017

Xiangjian Wang, Jiagang Wu, Brahim Dkhil, Baixiang Xu, Xiaopeng Wang, Guohua Dong, Guang Yang (D), and Xiaojie Lou

\section{ARTICLES YOU MAY BE INTERESTED IN}

Ferroelectric, pyroelectric, and piezoelectric properties of a photovoltaic perovskite oxide Applied Physics Letters 110, 063903 (2017); https://doi.org/10.1063/1.4974735

Large electrocaloric efficiency over a broad temperature span in lead-free $\mathrm{BaTiO}_{3}$-based ceramics near room temperature

Applied Physics Letters 111, 202902 (2017); https://doi.org/10.1063/1.5001366

$\mathrm{BaTiO}_{3}$-based piezoelectrics: Fundamentals, current status, and perspectives

Applied Physics Reviews 4, 041305 (2017); https: / doi.org/10.1063/1.4990046

\section{Lock-in Amplifiers up to $600 \mathrm{MHz}$}
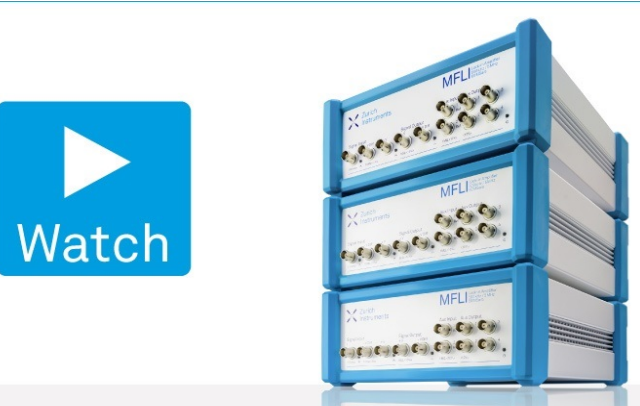


\title{
Enhanced electrocaloric effect near polymorphic phase boundary in lead-free potassium sodium niobate ceramics
}

\author{
Xiangjian Wang, ${ }^{1}$ Jiagang Wu, ${ }^{2}$ Brahim Dkhil, ${ }^{3}$ Baixiang $\mathrm{Xu},{ }^{4}$ Xiaopeng Wang, ${ }^{2}$ \\ Guohua Dong, ${ }^{5}$ Guang Yang, ${ }^{5}$ and Xiaojie Lou ${ }^{1, a)}$ \\ ${ }^{1}$ Frontier Institute of Science and Technology, and State Key Laboratory for Mechanical Behavior \\ of Materials, Xi' an Jiaotong University, Xi' an 710049, China \\ ${ }^{2}$ Department of Materials Science, Sichuan University, Chengdu 610064, China \\ ${ }^{3}$ Laboratoire Structures, Propriétés et Modélisation des Solides, CentraleSupélec, CNRS-UMR 8580, \\ Université Paris-Saclay, ChâtenayMalabry Cedex 92295, France \\ ${ }^{4}$ Institute of Materials Science, Technische Universität Darmstadt, 264287 Darmstadt, Germany \\ ${ }^{5}$ Electronic Materials Research Laboratory, Key Laboratory of the Ministry of Education \& \\ International Center for Dielectric Research, Xi' an Jiaotong University, Xi' an 710049, China
}

(Received 17 December 2016; accepted 28 January 2017; published online 8 February 2017)

\begin{abstract}
The electrocaloric (EC) effect in lead-free $(1-x)\left(\mathrm{K}_{0.48} \mathrm{Na}_{0.52}\right)\left(\mathrm{Nb}_{0.95} \mathrm{Sb}_{0.05}\right) \mathrm{O}_{3}-x \mathrm{Bi}_{0.5}\left(\mathrm{Na}_{0.82} \mathrm{~K}_{0.18}\right)_{0.5} \mathrm{ZrO}_{3}$ ceramics was investigated using an indirect thermodynamic method. Large $\mathrm{EC}$ temperature changes were obtained in the vicinity of a polymorphic phase boundary at $40 \mathrm{kV} / \mathrm{cm}$, e.g., $0.32 \mathrm{~K}$ at $359 \mathrm{~K}$ for $\mathrm{x}=0.03$, $0.51 \mathrm{~K}$ at $350 \mathrm{~K}$ for $\mathrm{x}=0.04$, and $0.48 \mathrm{~K}$ at $300 \mathrm{~K}$ for $\mathrm{x}=0.05$, respectively. These values are larger than the previous results at inter-ferroelectric phase transition and, more interestingly, are found to be comparable to those usually explored at the Curie temperature. The operational temperature window is broad near the polymorphic phase boundary due to the diffuseness of the phase transition. The enhanced electrocaloric effect is attributed to the formation of nanodomains near the polymorphic phase boundary, which reduces domain wall energy and facilitates the polarization rotation. The construction of a polymorphic phase boundary and the arrangement of coexisting phases at the nanoscale may open a promising route to explore EC materials. Published by AIP Publishing. [http://dx.doi.org/10.1063/1.4976026]
\end{abstract}

The environmentally friendly and low-cost electrocaloric (EC) refrigeration has attracted considerable attention to replace the conventional vapor-compression cooling technology. ${ }^{1,2}$ Since the discovery of a giant EC temperature change of $12 \mathrm{~K}$ in $\mathrm{PbZrTiO}_{3}$ (PZT) thin films, ${ }^{3}$ the investigations of the EC effect have been extensively conducted in both inorganic and organic ferroelectric materials. ${ }^{3-11}$ The EC effect is defined as the reversible adiabatic temperature change $\Delta \mathrm{T}$ in a dielectric material when an external electric field is applied or removed. Bulk EC materials own large cooling capacity compared with those of thin films, which are suitable for medium and large scale cooling devices. In the past decade, some large EC temperature changes have been reported in lead-based ceramics. ${ }^{71-13}$ However, the strict regulation on the utilization of lead in electronic devices restricts their potential applications as solid-state coolers.

Recently, lead-free ceramics have been investigated extensively, mainly in $\mathrm{BaTiO}_{3}$ (BTO)-based ${ }^{4,5,14,15}$ and $\mathrm{Na}_{0.5} \mathrm{Bi}_{0.5} \mathrm{TiO}_{3}$ (NBT)-based ceramics ${ }^{8,10}$ because of their large $\mathrm{EC}$ response. In BTO-based ceramics, large EC values have been obtained within a narrow temperature range around the temperature of the ferroelectric to paraelectric phase transition. Similarly, NBT-based ceramics exhibit large EC values near depolarization temperature. ${ }^{10}$ It is only recently that the EC effect has been investigated at a polymorphic phase boundary between two ferroelectric phases with different symmetries. Indeed, while weak, an EC peak was observed in lead-free $0.68 \mathrm{Ba}\left(\mathrm{Zr}_{0.2} \mathrm{Ti}_{0.8}\right) \mathrm{O}_{3}-0.32\left(\mathrm{Ba}_{0.7} \mathrm{Ca}_{0.3}\right) \mathrm{TiO}_{3}$ ceramics using a modified differential scanning calorimeter (DSC), ${ }^{16}$ implying

a)Electronic addresses: xlou03@mail.xjtu.edu.cn and xlou03@163.com that the EC effect can be also enhanced at a polymorphic phase boundary. It is worth mentioning that in the past decades, the lead-free $\mathrm{K}_{0.5} \mathrm{Na}_{0.5} \mathrm{NbO}_{3}(\mathrm{KNN})$-based ceramics have been widely studied to improve their piezoelectric and electromechanical responses through the design of a polymorphic phase boundary. ${ }^{17-20}$ However, there is only little research on the EC effect in these materials. In the relaxor composition of $0.85 \mathrm{~K}_{0.5}$ $\mathrm{Na}_{0.5} \mathrm{NbO}_{3}-0.15 \mathrm{SrTiO}_{3}$ ceramics, promising EC response with $\Delta \mathrm{T}$ exceeding $1.2 \mathrm{~K}$ at an electric field of $159 \mathrm{kV} / \mathrm{cm}$ was measured at room temperature by Rožič et al., ${ }^{6,21}$ as well as a $\Delta \mathrm{T} \sim 0.3 \mathrm{~K}$ under $20 \mathrm{kV} / \mathrm{cm}$ in ceramics ${ }^{22}$ of the modified solid solution $\left(\mathrm{Na}_{0.52} \mathrm{~K}_{0.48-\mathrm{x}}\right)\left(\mathrm{Nb}_{0.92-\mathrm{x}} \mathrm{Sb}_{0.08}\right) \mathrm{O}_{3}-\mathrm{xLiTaO}_{3}$. In order to explore for higher EC effect and reveal its physical mechanism; it is therefore crucial to further investigate ferroelectric materials at polymorphic phase transitions, and KNNbased ceramics appear as a rich playground for that purpose. Indeed, previous studies ${ }^{18-20}$ on KNN-based ceramics have indicated that doping with metal elements combined to solid solutions with other perovskite-type materials is an efficient route for bringing close to room temperature the various phase transition temperatures, such as the polymorphic ones between ferroelectric phases like orthorhombic-tetragonal $\left(\mathrm{T}_{\mathrm{O}-\mathrm{T}}\right)$, rhombohedral-orthorhombic $\left(\mathrm{T}_{\mathrm{R}-\mathrm{O}}\right)$, rhombohedral-tetragonal $\left(T_{R-T}\right)$, and the Curie temperature $\left(T_{c}\right)$ related to tetragonalcubic, i.e., ferroelectric-paraelectric transition. Here, the EC effect of (1-x) $\left(\mathrm{K}_{0.48} \mathrm{Na}_{0.52}\right)\left(\mathrm{Nb}_{0.95} \mathrm{Sb}_{0.05}\right) \mathrm{O}_{3}-\mathrm{xBi}_{0.5}\left(\mathrm{Na}_{0.82}\right.$ $\left.\mathrm{K}_{0.18}\right)_{0.5} \mathrm{ZrO}_{3}$ (abbreviated as KNNS-xBNKZ, with $\mathrm{x}=0.03$, 0.04 , and 0.05 ) ceramics is therefore studied. We utilized an indirect method based on the thermodynamic Maxwell relation, which was demonstrated to be well consistent with direct measurements using a modified differential scanning calorimeter in the case of KNN-based ceramics. ${ }^{22}$ 
Lead-free KNNS-xBNKZ ( $\mathrm{x}=0.03,0.04$, and 0.05$)$ ceramics were fabricated by conventional solid-state reaction. The procedure was reported elsewhere in details. ${ }^{19}$ X-ray diffraction (XRD Shimadzu 7000) was performed at room temperature between $20^{\circ}$ and $60^{\circ}$ in 2theta. The temperature dependence of the dielectric constant was measured in the range of $150 \mathrm{~K}-450 \mathrm{~K}$ at $100 \mathrm{~Hz}$ and $1 \mathrm{~V}$ using a HIOKI 3532 LCR impedance meter. The polarizationelectric field (P-E) loops at different temperatures were recorded at $10 \mathrm{~Hz}$ using a Radiant ferroelectric workstation. The specific heat capacity of the ceramics was obtained at zero electric field using a commercial TA Q2000 differential scanning calorimeter (DSC). The domain morphology of these ceramics was observed using a Transmission Electron Microscope (JEM-2100) operating with an accelerating voltage of $300 \mathrm{kV}$.

Fig. 1 displays the XRD patterns measured on the three KNNS-xBNKZ ceramics. A single perovskite phase is observed in all samples without any secondary impurity phase. The inset of Fig. 1 shows obvious splitting of the (200) peak at $\sim 45^{\circ}$ for all the ceramics, which indicates the phase coexistence between orthorhombic and tetragonal phases or rhombohedral and tetragonal ones associated with the polymorphic character as reported in the literature of KNN-based ceramics. ${ }^{18,19,23,24}$ Fig. 2 shows the dielectric constants and loss of the ceramics as a function of temperature measured from $150 \mathrm{~K}$ up to $450 \mathrm{~K}$ corresponding to the limitation of our experimental setup. For the KNNS003BNKZ ceramic, two dielectric anomalies are observed, with $\mathrm{T}_{\mathrm{O}-\mathrm{T}}$ at $\sim 325 \mathrm{~K}$ and $\mathrm{T}_{\mathrm{R}-\mathrm{O}}$ at $\sim 260 \mathrm{~K}$. As the BNKZ content increases, $\mathrm{T}_{\mathrm{O}-\mathrm{T}}$ and $\mathrm{T}_{\mathrm{R}-\mathrm{O}}$ merge into a single $\mathrm{T}_{\mathrm{R}-\mathrm{T}}$ at $278 \mathrm{~K}$ in the KNNS-004BNKZ ceramic. For the KNNS005BNKZ ceramic, $T_{R-T}$ and $T_{c}$ values are $263 \mathrm{~K}$ and $446 \mathrm{~K}$, respectively. Therefore, the KNNS-003BNKZ ceramic shows the coexistence of the orthorhombic and tetragonal phases, while the ceramics of $x=0.04$ and 0.05 own the rhombohedral and tetragonal phases with a higher amount of the rhombohedral phase for $\mathrm{x}=0.05$ (the inset of Fig. 1), in good agreement with the previous result. ${ }^{19}$ Note that the dielectric loss does not help to better define these critical temperatures as it is the case in the literature for other KNNbased ceramics. ${ }^{25,26}$

The evolution of heat capacity in KNNS-xBNKZ ceramics from $305 \mathrm{~K}$ to $520 \mathrm{~K}$ is shown in Fig. 3. The heat

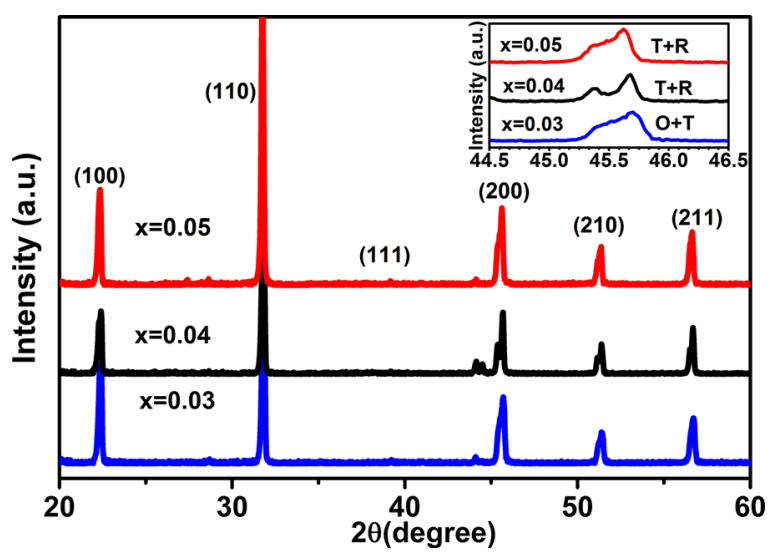

FIG. 1. The XRD patterns of the KNNS-xBNKZ ceramics.

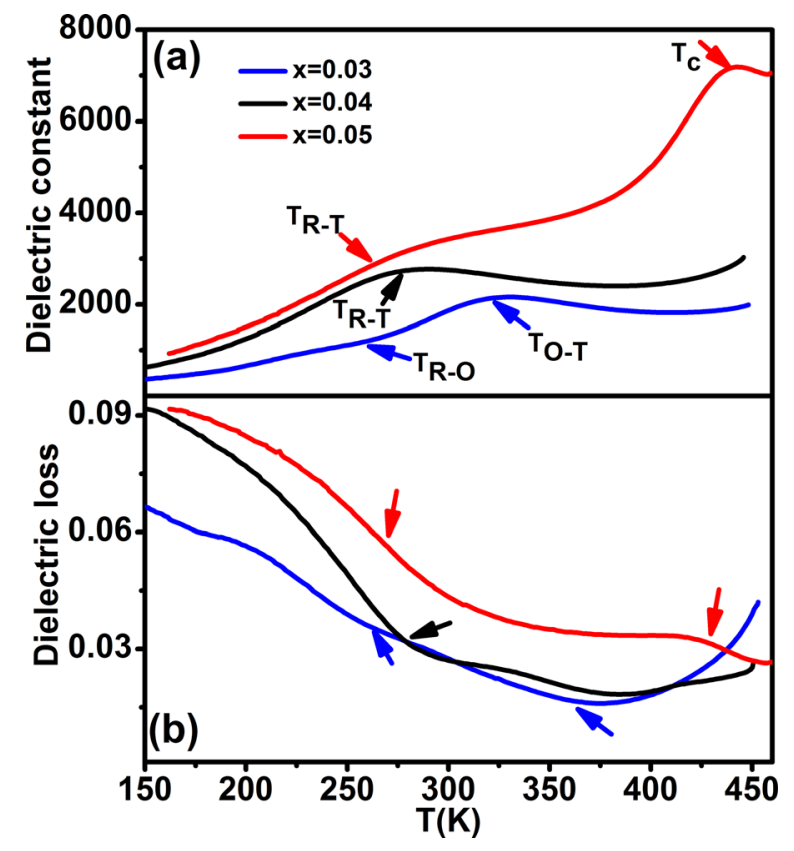

FIG. 2. The dielectric constant (a) and loss (b) of the KNNS-xBNKZ ceramics.

capacity increases with the increasing BNKZ content. For $\mathrm{x}=0.05$, the heat capacity measurement gives a peak (which is rather a kink) at $\sim 443 \mathrm{~K}$, which corresponds to $\mathrm{T}_{\mathrm{c}}$ obtained from the dielectric measurement. Similarly, heat flow peaks emerge at the Curie temperature for $\mathrm{x}=0.03$ (at $\mathrm{T}_{\mathrm{c}}=499 \mathrm{~K}$ ) and $\mathrm{x}=0.04\left(\right.$ at $\mathrm{T}_{\mathrm{c}}=470 \mathrm{~K}$ ), which is out of the range of our dielectric measurements. The magnitude of the peaks decreases with the increasing BNKZ content. In contrast, no heat flow signal for the polymorphic phase transitions can be easily evidenced in our experimental temperature range probably due to its diffuse character. ${ }^{22}$

Fig. 4 shows the polarization-electric field (P-E) loops of KNNS-xBNKZ ceramics measured at different temperatures. As the BNKZ content increases, the coercive field $\mathrm{E}_{\mathrm{c}}$ at room temperature decreases from $\mathrm{E}_{\mathrm{c}}=8.32 \mathrm{kV} / \mathrm{cm}$ for $\mathrm{x}=0.03$ to $\mathrm{E}_{\mathrm{c}}=6.47 \mathrm{kV} / \mathrm{cm}$ for $\mathrm{x}=0.05$. For KNNS$\mathrm{xBNKZ}$ ceramics with $\mathrm{x}=0.03$ and $\mathrm{x}=0.04$, the ferroelectric behavior is observed at all measured temperatures, while the KNNS-005BNKZ ceramic exhibits a spontaneous (at zero field) polarization decreasing consistently with the

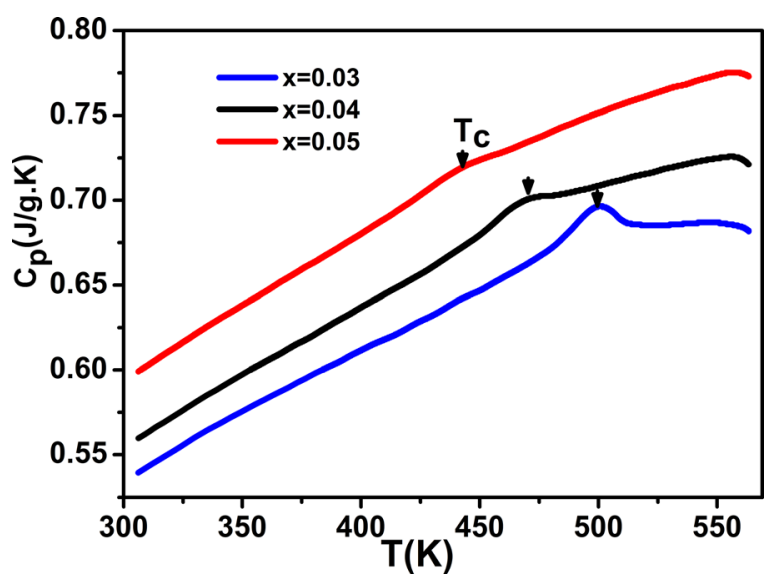

FIG. 3. The heat capacity of the KNNS-xBNKZ ceramics. 

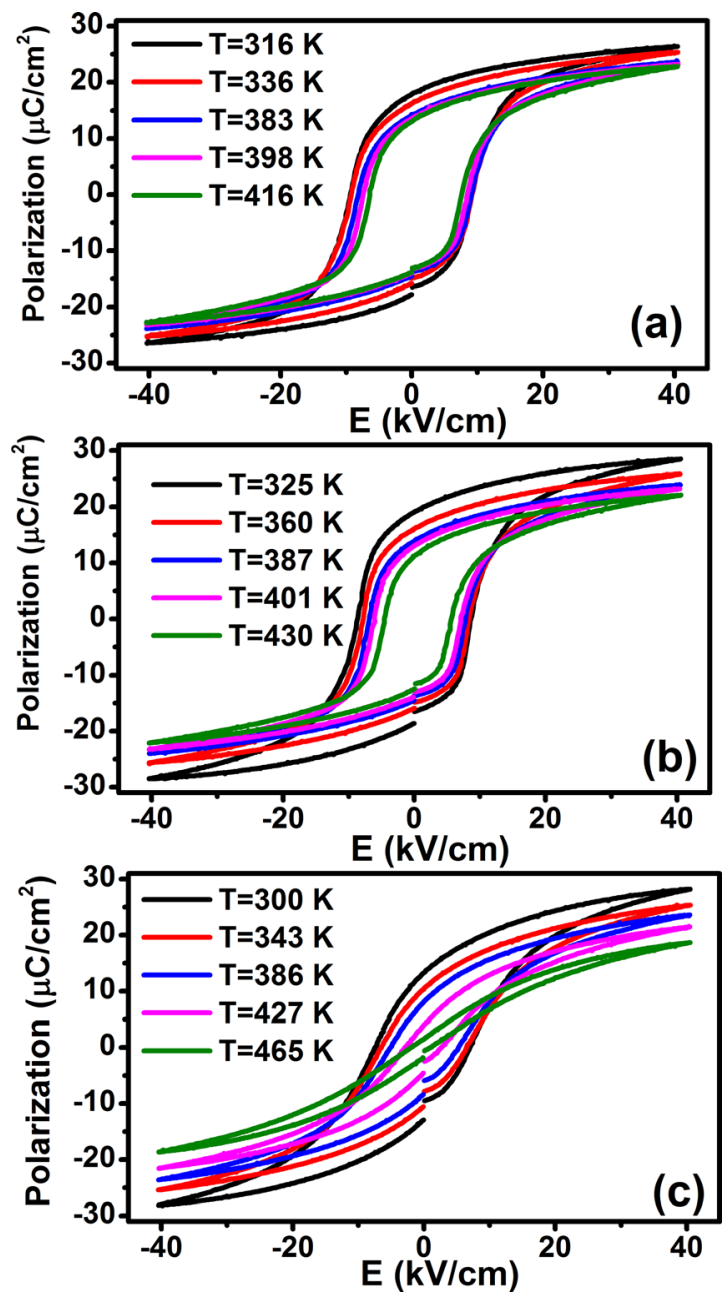

FIG. 4. The polarization-electric field (P-E) loops at $40 \mathrm{kV} / \mathrm{cm}$ for the KNNS-xBNKZ ceramics: (a) $\mathrm{x}=0.03$, (b) $\mathrm{x}=0.04$, and (c) $\mathrm{x}=0.05$ at different temperatures.

occurrence of the paraelectric phase above $T_{c} \sim 446 \mathrm{~K}$. For all the ceramics, the polarization at a fixed applied electric field decreases with increasing temperature, as shown in Figures 5(a)-5(c). The same trend was also observed in BTO-based ceramics. $4,5,14$

The adiabatic temperature change $\Delta \mathrm{T}$ was calculated using the indirect method based on the following thermodynamic Maxwell relation: ${ }^{3,13} \Delta \mathrm{T}=-\frac{T}{\rho C_{p}} \int_{E 1}^{E 2}\left(\frac{\partial P}{\partial T}\right)_{E} d E$, where $\rho$ is the density of the ceramic measured using the Archimedes method as reported elsewhere, ${ }^{27}$ and $E_{1}$ $\left(E_{1}=0 \mathrm{kV} / \mathrm{cm}\right)$ and $E_{2}$ are the initial and applied external electric fields, respectively. The heat capacity $\mathrm{C}_{\mathrm{p}}$ at room temperature is equal to $0.54 \mathrm{~J} / \mathrm{g} \mathrm{K}, 0.56 \mathrm{~J} / \mathrm{g} \mathrm{K}$, and $0.60 \mathrm{~J} / \mathrm{g} \mathrm{K}$ for $\mathrm{x}=0.03, \mathrm{x}=0.04$, and $\mathrm{x}=0.05$, respectively, and is considered temperature-dependent as we reported in Fig. 3. Previous studies ${ }^{5,28}$ have shown that the use of proper effective heat capacity allows us to get consistent EC values using indirect with respect to direct methods. The values of $(\partial P / \partial T)_{E}$ were then obtained from the temperature dependence of the polarization at a fixed electric field value (Figs. 5(a)-5(c)) by fitting the curves with a fourth-order polynomial equation.

Fig. 5 displays the electrocaloric temperature change $\Delta \mathrm{T}$ of the KNNS-xBNKZ ceramics at different external electric fields. Due to the dielectric breakdown at high temperature, the highest applied electric field is $45 \mathrm{kV} / \mathrm{cm}$ for KNNS003BNKZ and KNNS-004BNKZ and $40 \mathrm{kV} / \mathrm{cm}$ for KNNS$005 \mathrm{BNKZ}$. As expected, it can be seen that $\Delta \mathrm{T}$ is considerably enhanced as the electric field increases. For all these ceramics, the best EC response was obtained in the KNNS-004BNKZ composition, corresponding to the polymorphic state with the coexistence of rhombohedral and tetragonal phases. The maximum EC value at $40 \mathrm{kV} / \mathrm{cm}$ is $0.32 \mathrm{~K}$ at $359 \mathrm{~K}$ for $\mathrm{x}=0.03$, $0.51 \mathrm{~K}$ at $350 \mathrm{~K}$ for $\mathrm{x}=0.04$, and $0.48 \mathrm{~K}$ and $0.54 \mathrm{~K}$ at $300 \mathrm{~K}$ and $466 \mathrm{~K}$, respectively, for $\mathrm{x}=0.05$. It is remarkable to observe that a large EC value is obtained at the polymorphic phase boundary, and this value is comparable to that at $\mathrm{T}_{\mathrm{c}}$ as illustrated in the case of KNNS-005BNKZ (i.e., $0.48 \mathrm{~K}$ at the polymorphic transition against $0.54 \mathrm{~K}$ at the ferroelectricparaelectric transition). This result suggests further considering materials with polymorphic phase transition as potentially good electrocalorics. It is also intriguing as one would expect a much higher $\mathrm{EC}$ response at $\mathrm{T}_{\mathrm{c}}$ as the derivative of the polarization should diverge at $\mathrm{T}_{\mathrm{c}}$. Further works are required, and theoretical supports are strongly desired to better understand the origin of such strong EC values at the polymorphic phase transition. It is also worth mentioning that the EC peak is much stronger in the case of rhombohedral to tetragonal (R-T) ferroelectric phase transition $(x=0.04$ and $x=0.05)$ than for orthorhombic to tetragonal $(\mathrm{O}-\mathrm{T})$ ferroelectric phase transition $(\mathrm{x}=0.03)$. In order to provide some insights into the physical mechanism of the large EC effect near the polymorphic phase boundary, the domain morphology of these ceramics is depicted in Fig. 6. While no statistic has been done here, the typical size of the nanodomains varies from $\sim 57$ to $\sim 165 \mathrm{~nm}$ in these ceramics, which implies that the domain wall energy near the polymorphic phase boundary is rather low. ${ }^{29}$ Actually, the polarization anisotropy is decreased in the vicinity of rhombohedral (orthorhombic)-tetragonal ferroelectric phase transition due to the existence of a flattened free energy profile. ${ }^{30}$ According to the classical domain theory, ${ }^{31}$ the size of domains (D) is determined by the domain wall energy $\left(\mathrm{E}_{\mathrm{DW}}\right)$ as follows: $\mathrm{D} \sim \mathrm{E}_{\mathrm{DW}}^{1 / 2}$. The typical size of a single domain is found to be $\sim 165 \mathrm{~nm}$ for $\mathrm{x}=0.03, \sim 57 \mathrm{~nm}$ for $\mathrm{x}=0.04$, and $\sim 127 \mathrm{~nm}$ for $\mathrm{x}=0.05$, respectively, as shown in Fig. 6. The size of domains in the $x=0.04$ ceramic is (at least twice) smaller than the two other ceramics, which indicates that the domain wall energy is the lowest for KNN-004BNKZ. Therefore, the polarization can easily rotate from one phase to another under an external electric field, which can result in a bigger entropy change in the KNNS-004BNKZ ceramic and explain its highest EC value. It is worth mentioning that a low coercive field might be an indication of an "easier" polarization rotation. Indeed, we compare the P-E loops corresponding to the temperature at which the EC response is the biggest, and it is found that the coercive field is lower for KNNS004BNKZ $\left(\mathrm{E}_{\mathrm{c}} \sim 6.5 \mathrm{kV} / \mathrm{cm}\right.$ at $\left.\sim 350 \mathrm{~K}\right)$ and KNNS-005BNKZ $\left(\mathrm{E}_{\mathrm{c}} \sim 6.5 \mathrm{kV} / \mathrm{cm}\right.$ at $\left.\sim 300 \mathrm{~K}\right)$ than for KNNS-003BNKZ $\left(\mathrm{E}_{\mathrm{c}}\right.$ $\sim 8 \mathrm{kV} / \mathrm{cm}$ at $\sim 360 \mathrm{~K})$. Nonetheless, we believe that not only the coercive field is important but also the shape of the P-E loop, which indicates somehow the energy required for the polarization change under an electric field and the temperature evolution of the polarization from which we basically extract the EC response. In addition, we argue that as the highest 

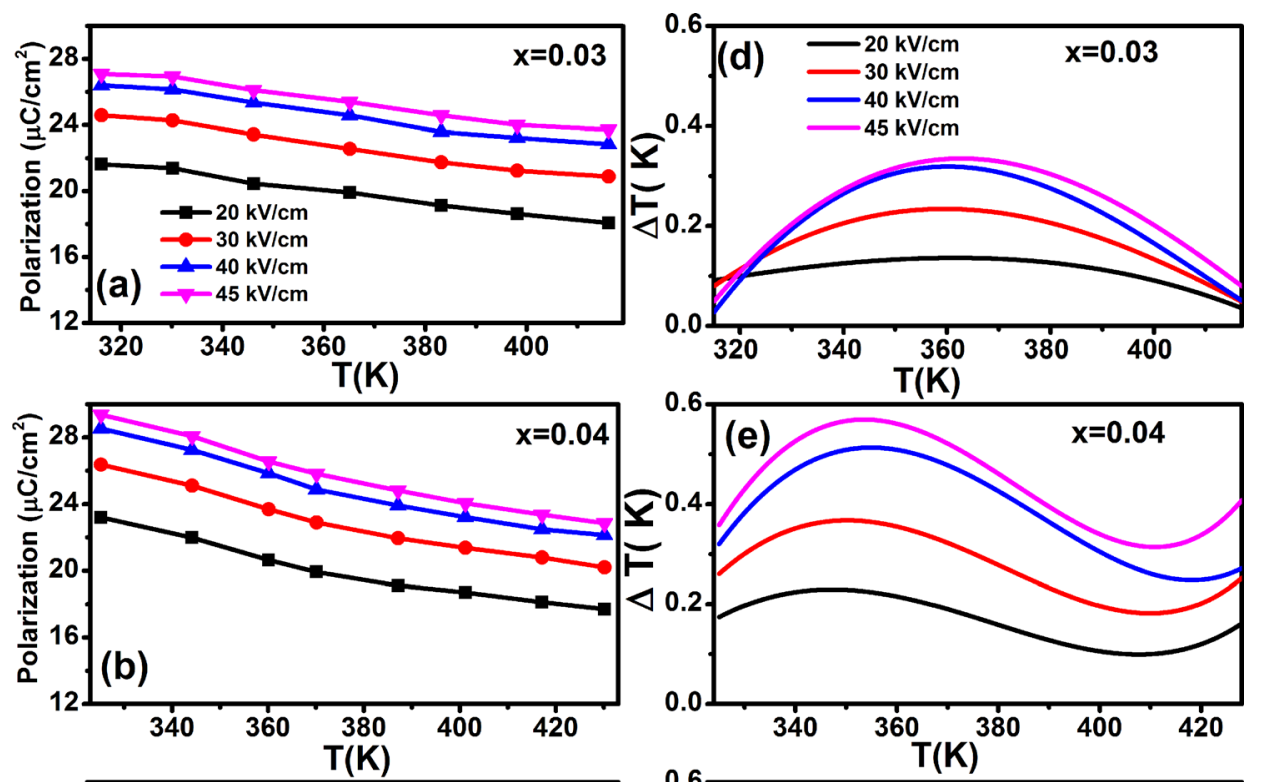

FIG. 5. The polarization as a function of temperature in KNNS-xBNKZ for (a) $\mathrm{x}=0.03$, (b) $\mathrm{x}=0.04$, and (c) $\mathrm{x}=0.05$ and the electrocaloric temperature change in KNNS-xBNKZ for (d) $\mathrm{x}=0.03,(\mathrm{e}) \mathrm{x}=0.04$, and (f) $\mathrm{x}=0.05$.
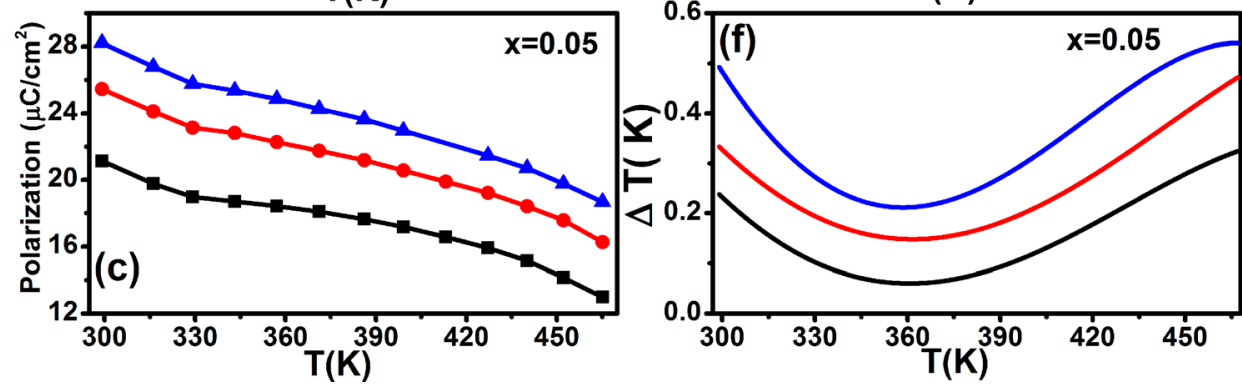

electromechanical responses are usually associated with the easy rotation of the polarization, the piezocaloric effect can also contribute to the total EC signal.

Let us now compare the EC response of KNNS-XBNKZ ceramics with that of other lead-free electrocalorics. As the reported results were obtained using different applied electric fields, it is useful to compare the EC strength $(\Delta \mathrm{T} / \Delta \mathrm{E})$. The maximum EC strengths obtained in KNNS-003BNKZ, KNNS-004BNKZ, and KNNS-005BNKZ are $0.08 \mathrm{~K} \mathrm{mm/}$ $\mathrm{kV}, 0.13 \mathrm{~K} \mathrm{~mm} / \mathrm{kV}$, and $0.12 \mathrm{~K} \mathrm{~mm} / \mathrm{kV}$, respectively. These EC strengths are comparable to or higher than the values observed in compositions where different phases coexist such as $0.07-0.09 \mathrm{~K} \mathrm{~mm} / \mathrm{kV}$ in $(1-\mathrm{x}) \mathrm{Ba}\left(\mathrm{Zr}_{0.2} \mathrm{Ti} 0.8\right) \mathrm{O}_{3}-\mathrm{X}$ $\left(\mathrm{Ba}_{0.7} \mathrm{Ca}_{0.3}\right) \mathrm{TiO}_{3}$ ceramics $^{16}$ and $0.10-0.18 \mathrm{~K} \mathrm{~mm} / \mathrm{kV}$ in $\left(\mathrm{Na}_{0.52} \mathrm{~K}_{0.48-\mathrm{x}}\right)\left(\mathrm{Nb}_{0.92-\mathrm{x}} \mathrm{Sb}_{0.08}\right) \mathrm{O}_{3}-\mathrm{xLiTaO}_{3}$ ceramics. $^{22}$ The EC strength in KNNS-004BNKZ is superior to that $(\sim 0.12 \mathrm{~K}$ $\mathrm{mm} / \mathrm{kV}$ ) in the relaxor $0.85 \mathrm{~K}_{0.5} \mathrm{Na}_{0.5} \mathrm{NbO}_{3}-0.15 \mathrm{SrTiO}_{3}$ ceramic $^{6,21}$ at the ferroelectric to paraelectric phase transition. Finally, the temperature window of the EC signal is also a crucial parameter for cooling applications of EC materials. In the case of the KNNS-004BNKZ ceramic, the EC value decreases only by about $15 \%$ in a temperature range of $30 \mathrm{~K}$ because of the diffuseness of the polymorphic phase boundary.

In conclusion, we studied the EC effect in lead-free KNNS-xBNKZ ceramics using an indirect method and indicated that this system exhibits good EC responses. Maximum EC responses were observed in these ceramics near the polymorphic phase boundary. The EC temperature change is $0.32 \mathrm{~K}$ at $359 \mathrm{~K}$ for the ceramics with $\mathrm{x}=0.03$, $0.51 \mathrm{~K}$ at $350 \mathrm{~K}$ for $\mathrm{x}=0.04$, and $0.48 \mathrm{~K}$ at $300 \mathrm{~K}$ in $\mathrm{x}=0.05$, under an electric field of $40 \mathrm{kV} / \mathrm{cm}$ with a broad temperature window due to the diffuseness of the polymorphic phase boundary. These EC strengths are even larger and comparable to those in some ceramics observed at the polymorphic phase boundary or the Curie temperature. The electrocaloric response near the polymorphic phase boundary can be explained by the presence of nanodomains, which
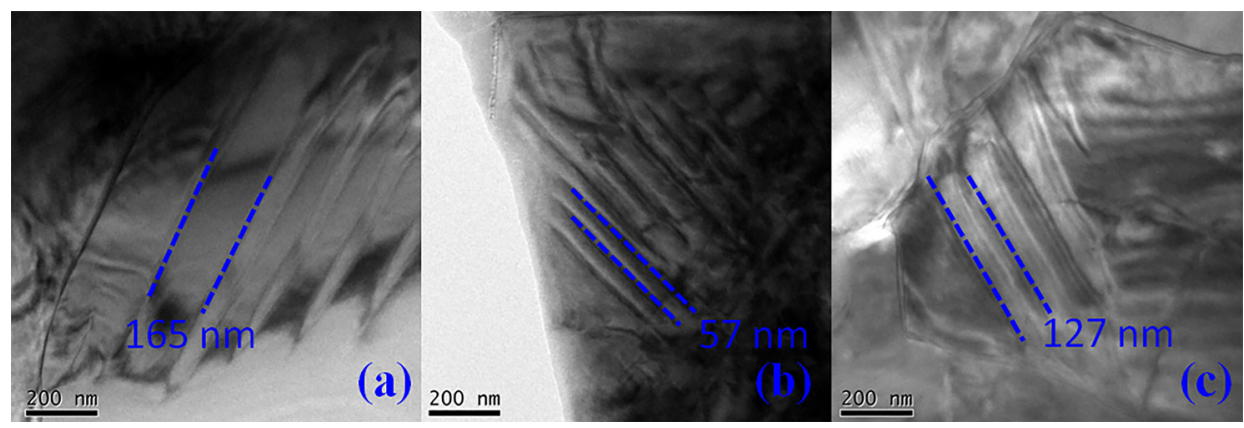

FIG. 6. TEM measurements on the domain morphology in KNNS-xBNKZ for (a) $\mathrm{x}=0.03$, (b) $\mathrm{x}=0.04$, and (c) $\mathrm{x}=0.05$. 
reduces domain wall energy and facilitates the polarization rotation. Finally, it is believed that larger EC temperature changes could be obtained via the modification of the ferroelectric nanodomains and enhancement of the breakdown field. Such results will provide a promising route for improved EC materials through the construction of a welldesigned polymorphic phase boundary.

This work was supported by the National Science Foundation of China (NSFC Nos. 51372195 and 41372055), Fundamental Research Funds for Central Universities (2013JDGZ03), the CSS project (Grant No. YK20150602006), and Grant No. IRT13034. X. J. Lou would like to thank the "One Thousand Youth Talents" program for support. B. X. Xu thanks the financial support of the project of German Science Foundation (DFG Xu121/1) in the Priority program (DFG SPP1599). B. Dkhil acknowledges a public grant overseen by the French National Research Agency (ANR) as part of the "Investissements d'Avenir" program (Grant No. ANR10-LABX-0035, Labex NanoSaclay) and Fonds National de la Recherche du Luxembourg (FNR) through InterMobility Project No. 16/1159210 "MULTICALOR."

${ }^{1}$ J. Scott, Annu. Rev. Mater. Res. 41, 229-240 (2011).

${ }^{2}$ T. Correia and Q. Zhang, Electrocaloric Materials (Springer, 2014).

${ }^{3}$ A. Mischenko, Q. Zhang, J. Scott, R. Whatmore, and N. Mathur, Science 311(5765), 1270-1271 (2006).

${ }^{4}$ B. Asbani, J.-L. Dellis, A. Lahmar, M. Courty, M. Amjoud, Y. Gagou, K. Djellab, D. Mezzane, Z. Kutnjak, and M. El Marssi, Appl. Phys. Lett. 106(4), 042902 (2015).

${ }^{5}$ X. Wang, F. Tian, C. Zhao, J. Wu, Y. Liu, B. Dkhil, M. Zhang, Z. Gao, and X. Lou, Appl. Phys. Lett. 107(25), 252905 (2015).

${ }^{6}$ B. Rožič, J. Koruza, Z. Kutnjak, G. Cordoyiannis, B. Malič, and M. Kosec, Ferroelectrics 446(1), 39-45 (2013).

${ }^{7}$ B. Rožič, M. Kosec, H. Uršič, J. Holc, B. Malič, Q. Zhang, R. Blinc, R. Pirc, and Z. Kutnjak, J. Appl. Phys. 110(6), 064118 (2011).

${ }^{8}$ Y. Bai, G.-P. Zheng, and S.-Q. Shi, Mater. Res. Bull. 46(11), 1866-1869 (2011).
${ }^{9}$ S. Lu, B. Rožič, Q. Zhang, Z. Kutnjak, and B. Neese, Appl. Phys. Lett. 98(12), 122906 (2011).

${ }^{10}$ F. Le Goupil and N. M. Alford, APL Mater. 4(6), 064104 (2016).

${ }^{11}$ L. Shebanovs, K. Borman, W. N. Lawless, and A. Kalvane, Ferroelectrics 273(1), 137-142 (2002).

${ }^{12}$ J. Hagberg, A. Uusimäki, and H. Jantunen, Appl. Phys. Lett. 92(13), 132909 (2008).

${ }^{13}$ B. Tuttle and D. Payne, Ferroelectrics 37(1), 603-606 (1981).

${ }^{14}$ Y. Bai, X. Han, and L. Qiao, Appl. Phys. Lett. 102(25), 252904 (2013).

${ }^{15}$ G. Singh, V. Tiwari, and P. Gupta, Appl. Phys. Lett. 103(20), 202903 (2013).

${ }^{16}$ M. Sanlialp, V. V. Shvartsman, M. Acosta, and D. C. Lupascu, J. Am. Ceram. Soc. 99(12), 1-9 (2016).

${ }^{17}$ F. Rubio-Marcos, R. López-Juárez, R. E. Rojas-Hernandez, A. del Campo, N. Razo-Pérez, and J. F. Fernandez, ACS Appl. Mater. Interfaces 7(41), 23080-23088 (2015).

${ }^{18}$ R. Zuo and J. Fu, J. Am. Ceram. Soc. 94(5), 1467-1470 (2011).

${ }^{19}$ X. Wang, J. Wu, D. Xiao, J. Zhu, X. Cheng, T. Zheng, B. Zhang, X. Lou, and X. Wang, J. Am. Chem. Soc. 136(7), 2905-2910 (2014).

${ }^{20}$ J. Wu, D. Xiao, and J. Zhu, Chem. Rev. 115(7), 2559-2595 (2015).

${ }^{21}$ J. Koruza, B. Rožič, G. Cordoyiannis, B. Malič, and Z. Kutnjak, Appl. Phys. Lett. 106(20), 202905 (2015).

${ }^{22}$ J. Li, Y. Bai, S. Qin, J. Fu, R. Zuo, and L. Qiao, Appl. Phys. Lett. 109(16), 162902 (2016).

${ }^{23}$ K. Xu, J. Li, X. Lv, J. Wu, X. Zhang, D. Xiao, and J. Zhu, Adv. Mater. 28(38), 8519-8523 (2016).

${ }^{24}$ K. Wang, F.-Z. Yao, W. Jo, D. Gobeljic, V. V. Shvartsman, D. C. Lupascu, J.-F. Li, and J. Rödel, Adv. Funct. Mater. 23(33), 4079-4086 (2013).

${ }^{25}$ Y. Guo, K.-I. Kakimoto, and H. Ohsato, Appl. Phys. Lett. 85(18), 4121-4123 (2004).

${ }^{26}$ B.-Q. Ming, J.-F. Wang, P. Qi, and G.-Z. Zang, J. Appl. Phys. 101(5), 054103 (2007).

${ }^{27}$ T. Zheng and J. Wu, ACS Appl. Mater. Interfaces 8(14), 9242-9246 (2016).

${ }^{28}$ X. Moya, E. Stern-Taulats, S. Crossley, D. González-Alonso, S. KarNarayan, A. Planes, L. Mañosa, and N. D. Mathur, Adv. Mater. 25(9), 1360-1365 (2013).

${ }^{29}$ G. A. Rossetti, A. G. Khachaturyan, G. Akcay, and Y. Ni, J. Appl. Phys. 103(11), 114113 (2008).

${ }^{30}$ D. Damjanovic, Appl. Phys. Lett. 97(6), 062906 (2010).

${ }^{31}$ M. E. Lines and A. M. Glass, Principles and Applications of Ferroelectrics and Related Materials (Oxford University Press, 1977). 